\title{
Speech therapy intervention in a teenager with autism spectrum disorder: a case report
}

Taisa Ribeiro de Souza Oliveira(1) Andreza Alves Nascimento(1) Ariane Damasceno Pellicani ${ }^{(1)}$ Geciane Maria Xavier Torres ${ }^{(1)}$ Kelly da Silva ${ }^{(1)}$ Raphaela Barroso Guedes-Granzotti ${ }^{(1)}$

(1) Universidade Federal de Sergipe - UFS, Lagarto, Sergipe, Brasil.

Work developed in the Department of Speech, Language and Hearing Sciences of the Federal University of Sergipe,

Professor Antônio Garcia Filho Campus.

Conflict of interests: Nonexistent

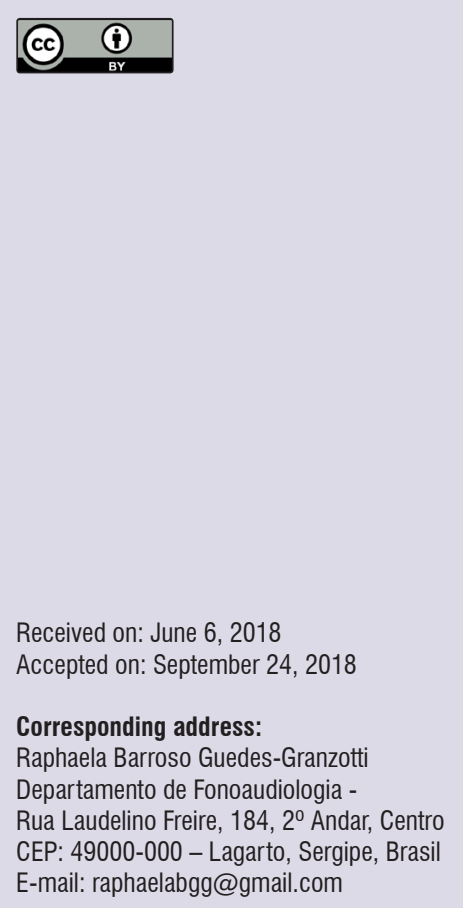

\section{ABSTRACT}

Autism Spectrum Disorder is a neurodevelopmental disorder that affects socio-communicative and behavioral abilities. In the language aspect, there is a greater impairment at the pragmatic level and in non-verbal aspects. The objective of this study was to characterize the severity of Autism Spectrum Disorder in an adolescent, pre-and post-speech-language therapy, and describe the process of speech-language intervention using Picture Exchange Communication System allied to the principles of behavioral analysis applied to language. The Autism Treatment Evaluation Checklist with the parents was applied. Then, a therapeutic program of 14 sessions of 50 minutes was developed, one per week, and then the questionnaire was reapplied. In the course of the therapeutic process, it was possible to observe an increase in the number of figure exchanges independently, an increase in the number of vocalizations with communicative intention or functional speech, longer time of visual contact and social smile, reduction of inappropriate behaviors with a significant improvement in the Autism Treatment Evaluation Checklist score.

Keywords: Autistic Disorder; Communication; Language; Speech, Language and Hearing Sciences; Rehabilitation of Speech and Language Disorders 


\section{INTRODUCTION}

Autism Spectrum Disorder (ASD) is a disorder of neurological development, characterized by a set of behavioral conditions with impairments in two main domains: socio-communicative and behavioral ones (fixed or repetitive behaviors), with the onset of symptoms occurring from birth or early childhood' ${ }^{1}$.

This definition is based on the new classification described in the Diagnostic and Statistical Manual of Mental Disorders (DSM-5) $)^{2}$, which standardizes the diagnosis and aims to increase the specificity of the diagnosis of ASD. The clinical condition can present very different levels of severity, making individuals with the same diagnosis present very different clinical manifestations, so the term "spectrum." In this new classification, classic autism, Asperger's disorder, childhood disintegrative disorder and the developmental disorder of development without other specification are included in the ASD.

Language alterations, although not an exclusive diagnostic criterion for autism, play a central role in the characterization of ASD, since there are usually delays and deviations in the development of autism, observing a greater impairment at the pragmatic level and in non-verbal aspects. It is possible to notice still in the first months of life the absence of ocular contact, reduced number of gestures and facial expressions, babbling and response to sounds ${ }^{3}$.

Furthermore, the precursors of spoken language, such as the ability to imitate behaviors, play with objects and shared attention (triadic attention), are impaired in children with autism. Echolalia (immediate or late), inappropriate use of pronouns, immature grammatical structure, and rigidity of meanings are also observed ${ }^{4}$.

During adolescence, individuals with ASD may experience limited social experiences, maintaining relationships only with close people, such as family members. In order to change this mode of individual and social functioning, speech, language and hearing sciences therapy work is fundamental, since the socio-cognitive functioning of autistic adolescents is closely associated with the communicative profile and, therefore, the more effective the communication, more the subjects can act socially and develop ${ }^{5}$.

In addition, first-line treatments for children and adolescents with autism should include psychosocial treatments and educational interventions, with the goal of maximizing language acquisition, improving social and communicative skills, and ending maladaptive behaviors. Currently, however, there are no drug treatments approved by the Food and Drug Administration (FDA) for autism. Despite limited empirical support, psychopharmacological treatment appears to be common in clinical practice and targets specific symptoms that accompany nuclear symptoms and which severely impair the functioning of the individual. This commonly does not allow for educational and behavioral interventions (aggression, selfdestructive behavior, compulsive rituals, low frustration tolerance with explosive attacks, hyperactivity, etc.) ${ }^{6}$.

Treatments based on the principles of applied behavior analysis, such as the ABA (Applied Behavior Analysis), associated with a Picture Exchange Communication System (PECS), have been shown to be efficient, enabling significant improvements in communication and, consequently, better quality of life for these patients ${ }^{7,8}$.

However, recent studies question the assertions that the ABA is the only model with scientifically proven results and admit the need for more research on the results of intervention processes, with relevant casuistry and clear criteria for inclusion and evaluation of the results. Therefore, any proposal for intervention can be considered more efficient or productive than others ${ }^{9,10}$.

Therefore, this case report aimed to characterize parents' perceptions about the severity of Autism Spectrum Disorder in an adolescent, pre-and postSpeech, Language and Hearing Sciences therapy, and describe the intervention process using as communication model exchange of PECS figures coupled with the principles of ABA behavioral analysis applied to language.

\section{CASE PRESENTATION}

With the ethical principles fulfilled, the research was approved by the Research Ethics Committee of the Federal University of Sergipe (No. 2.321.274) and the mother, the legal representative of the case here presented, signed the Free and Informed Consent Form. This study is based on the case report of Speech, Language and Hearing Sciences therapy to a 13-year-old female, diagnosed with severe Autistic Spectrum Disorder (ASD) by a neuropediatrician.

The pregnancy was uneventful, she was born preterm, did not need oxygen and was breastfed until the age of two. According to parents' reports, up to a year and two months, the child presented normal development, for example, spoke / valo / for cavalo (Portuguese for horse) and interacted well, but from that age, she regressed significantly regarding speech, 
behavior and interaction, no longer presenting interest in sharing activities and situations with their interlocutors. The diagnosis of ASD was performed when she was three years old and, since then, she has had weekly consultations with a speech therapist, an occupational therapist and an equine therapy. However, the mother reports that she has observed few gains during this period. She currently uses the neuroleptic drug Risperidone for her hyperactivity; attends regular school, is in the $9^{\text {th }}$ grade of elementary school, only as a form of socialization. She does not independently perform any of the activities of daily living depending always on a caregiver, and communicates only with gestures indicating what she desires.

She began attending at the Language Outpatient Clinic of a Clinic School of Speech Language and Hearing Sciences at a Federal University on September 16,2016 , with the main complaint of the parents being the communication difficulty due to the little progress made so far with the previous interventions.

\section{RESULTS}

Initially, to assess the level of severity of autism and measure the effects of the treatment, the mother completed the Autism Treatment Evaluation Checklist (ATEC) ${ }^{11}$, a scale specifically developed to assess the effectiveness of treatments for autism and covering four areas of development and behavior, being: I. Language, (14 items) II. Sociability (20 items), III. Cognitive / Sensory Consciousness (18 items) and IV. Behavior (25 items), with the higher the score, the more severe the table presented. The score obtained by the patient was I $=26, I I=29, I I I=29$ and IV $=27$, Total $=$ 111 , indicating from 90 to $100 \%$ of severity.

For the establishment of bond and evaluation through behavioral observation, interactive toys, plug-in blocks, pop-up books and exploration of the therapeutic environment were used as resources. The patient presented verbal, especially echolalia, and non-verbal stereotypies, such as flapping (repetitive hand movements); a very restricted repertoire of activities, demonstrating exacerbated interest in music and on the cell phone. It has been observed that the patient walks frequently on tiptoe, has little visual contact, presents restlessness, hearing (always covering the ears) and tactile hypersensitivity.

Regarding the pragmatic aspect of language, it presented intentional communication with primary functions through elementary non-symbolic gestures and some isolated words (speaks "tchau" / $\mathrm{s}$ au / and "beijo" / bezu / when requested, associated with the gesture, besides calling the name of the brother and of the nanny) with restricted participation in dialogic activity. She comprises orders with up to two actions when linked to the immediate context. Due to the serious deficit in the pragmatic aspect, other aspects of the language such as phonology, morphosyntax and semantics are not possible to be evaluated. An audiological evaluation attempt was performed, however, the patient did not allow the tests to be carried out.

Then, a therapeutic program of 14 sessions of 50 minutes each was developed, one per week, with the main therapeutic goal being to increase the communicative skills, aiming at improving the social and familial insertion of the adolescent. The specific objectives were to promote the teaching of the PECS; create a structured training environment; encourage interaction; promote autonomy in activities of daily living (ADL).

To identify the words to be used in the initial Speech, Language and Hearing Sciences therapy intervention period with PECS, the Planilha de Seleção deVocabulário ${ }^{12}$, proposed by the own system manual, was used. In this worksheet, family members listed 5 to 10 items most commonly used in each category: food, beverages, activities, social games, frequented places, leisure activities, family members and non-pleasurable activities.

After selecting the reinforcers of the adolescent, the figures were printed, plastified and Velcro was fixed in the back, so that they could be placed and detached easily in the folder of communication. Later, it was observed that the patient was uncomfortable with the noise of the Velcro. Regarding it, it was decided to use a magnet sheet (magnetic blanket), which was well accepted by the patient. The folder containing colored plastic sheets for sorting the types of reinforcers (food, objects, toys, verbs like, for example, "I want") made it possible to fix and detach the communication figures easily.

Before starting the teaching of the PECS phases, a baseline was performed in the initial sessions, whose purpose was to verify whether or not the patient had the ability to request an item using an exchange of figures. During this phase, strategies that facilitated the patient's familiarity with PECS as charts with pictorial representation on undressing and dressing, dolls to wear (sticker on the board) and interactive toys were used. 
During all the phases, the ABA-based hierarchy of tips was used to facilitate learning. The tips are phased out, that is, one should start with a more intrusive tip (physical help - pick up the patient's hand and take off and deliver or point a picture) and gradually move on to lighter gesture aid - just pointing the patient's hand to the photo or just pointing the photo the patient should pick).

In phase I, the behavior taught to "change the figure" was composed of a chain of three responses: 1 - pick the figure, 2 - extend the arm towards the therapist and 3 - put the figure in the therapist's hand. Each response was taught separately, according to the patient's ability. The reinforcing stimulus of this phase was the cellular one, since, among the possibilities, this one was the one that presented greater reinforcing value for the patient (Figure 1).
In phase II, the goal was to work the spontaneity for the adolescent to interact with the therapist in the exchange. Three steps were necessary to teach this phase, as can be seen in Figure $1^{13}$. The distance between the therapist and the adolescent gradually increases and, afterward, it also increases between the adolescent and the binder. The phase ends when the patient performs $80 \%$ of the attempts independently.

In phase III, the objective was to choose the figure of an item having, at the same time, provided two or more stimuli (discrimination). The available stimuli were chosen to be modified: first a reinforcing stimulus and a neutral stimulus were available, then, two reinforcing stimuli and, finally, the response of choice should occur between several neutral stimuli and the reinforcers. The arranged figures, therefore, had their amount increased and their size decreased throughout phase III.

\begin{tabular}{|c|c|c|c|c|c|}
\hline Phases & Objetives & Steps & $\begin{array}{c}\text { Reinforcer objects } \\
\text { used }\end{array}$ & $\begin{array}{l}\text { Sessions/ } \\
\text { Attempts }\end{array}$ & Results \\
\hline $\begin{array}{c}\text { Phase I } \\
\text { Physical Exchange }\end{array}$ & $\begin{array}{l}\text { - Initiate interaction. } \\
\text { - Verbal Operators: } \\
\text { Issue commands (ask) } \\
\text { and tacts (name). }\end{array}$ & $\begin{array}{l}\text { A. A. Start teaching with full } \\
\text { reinforcement (the therapist can } \\
\text { physically help the patient to pick } \\
\text { the figure); } \\
\text { B. Gradual reinforcement; } \\
\text { C. Reducing the "open hand" clue. }\end{array}$ & - Cellphone; & $\begin{array}{c}5 \text { sessions } \\
\text { (50 attempts) }\end{array}$ & $80 \%$ \\
\hline $\begin{array}{c}\text { Phase II } \\
\text { Increased spontaneity }\end{array}$ & $\begin{array}{l}\text { - Insist on interaction. } \\
\text { - Verbal Operators: } \\
\text { Issue commands (ask) } \\
\text { and tacts (name). }\end{array}$ & $\begin{array}{l}\text { A. Allow the patient to stay for } 10 \text { to } \\
15 \text { seconds with the object that } \\
\text { was requested; } \\
\text { B. Increase the distance between } \\
\text { the patient and the therapist } \\
\text { (gradually); } \\
\text { C. Increase the distance between the } \\
\text { patient and the figure (gradually) }\end{array}$ & $\begin{array}{l}\text { - M\&Ms; } \\
\text { - Fandangos; } \\
\text { - EasterEgg; } \\
\text { - Cellphone; } \\
\text { - Strolling around the } \\
\text { room, associated } \\
\text { to listening to } \\
\text { music. } \\
\end{array}$ & $\begin{array}{c}4 \text { sessions } \\
\text { (40 attempts) }\end{array}$ & $80 \%$ \\
\hline $\begin{array}{l}\text { Phase III } \\
\text { Discrimination of } \\
\text { Figures }\end{array}$ & $\begin{array}{l}\text { - Discriminate pictures } \\
\text { of favorite items. } \\
\text { - Verbal Operators: } \\
\text { Issue commands } \\
\text { (ask) and tacts } \\
\text { (name). }\end{array}$ & $\begin{array}{l}\text { A. Begins with highly desirable and } \\
\text { non-preferred object; } \\
\text { B. Two highly desirable objects are } \\
\text { used. }\end{array}$ & $\begin{array}{l}\text { - } \text { Strolling around the } \\
\text { room, associated } \\
\text { to listening to } \\
\text { music. M\&Ms } \\
\text { - } \text { Ball } \\
\text { - Cellphone } \\
\text { - } \\
\text { Marshmallow } \\
\end{array}$ & $\begin{array}{c}5 \text { sessions } \\
\text { (50 attempts) }\end{array}$ & $90 \%$ \\
\hline
\end{tabular}

Source: Prepared by the authors based on Jesus, Oliveira and Rezende (2017) ${ }^{13}$

Figure 1. Description of the phases of the Picture Exchange Communication System (PECs) and results obtained 
In addition, to encourage autonomy in activities of daily living, an image was used showing a sequence of step-by-step figures on how to brush teeth, since this is the activity that the family considered a priority. The procedure was explained and performed in the therapy room and later, this figure was given to the family members with the orientation that the figure was to be positioned in the bathroom, in an easy-to-view place, so that training could also be performed at home.

At the end of each session the family was guided on what was worked on and how to continue the learning developed in the family environment. Besides giving precise information about the development of the teenager and accepting possible doubts.

In the course of the therapeutic process, it was possible to notice an increase in the number of figure exchanges independently, an increase in the number of vocalizations with communicative intention or functional speech, longer time of visual contact and social smile, reduction of inappropriate behaviors with a significant improvement on the score of the ATEC questionnaire, since after 14 intervention sessions the mother answered the questionnaire again and the results were as follows: $I=19, I I=13, I I I=15$ and IV $=20$, total $=$ 67 , indicating reduction of the level of seriousness from 50 to $59 \%$.

\section{DISCUSSION}

The main objective at the beginning of therapy with a patient with autism is to establish the therapeutic setting to get in touch with her uniqueness, to establish a bond and a therapeutic relationship, and to gradually work the barriers imposed by the spectrum. It is indispensable to consider the primitive initiatives of interaction and communication and vague signs of novelty in a stereotyped and rigid world ${ }^{14}$.

During the first sessions, the patient presented agitated behavior and with many stereotyped movements, frequently cried during the attendance, thus, presenting little communicative intention. Facing this, we sought to identify the factors that were interfering, through changes in the environment, such as turning off the fan, reducing the intensity of the therapist's voice, making the environment more attractive and colorful, and not restricting the patient to sit around, encouraging her to explore the therapy room.

A recent study ${ }^{15}$ conducted by the American Speech Language Hearing Association to determine the intervention used by speech therapists in children with ASD, as well as the intervention techniques used with different age groups and the training received before using the intervention techniques demonstrated that the System of Figure Exchanges, along with Social Skills Training, Expanded and Alternative Communication, and Social Stories are the most commonly used techniques. The importance of using practices based on established or emerging evidence is also reported.

The PECS is composed of six phases, but this work describes the application of the first three, which are: 1) physical exchange, 2) increase of spontaneity and 3) discrimination of figures. The PECS aims to facilitate the acquisition of functional communication skills, based on the principles of Skinner's verbal behavior, where verbal operants (functional units of language) are taught systematically, with strategies used to teach the patient to "request" and "comment". The main operants taught are: touch (name), command (ask), intra-verbal (answer questions) ${ }^{16}$. That is, the individual does not need to have oral language to use the principles of teaching verbal behavior. It can be said that the command is the verbal operant that directly benefits the speaker, because the person makes the request and it is reinforced by getting something in return, therefore, it is a naturally reinforcing operant. It is then the first form of language to be acquired ${ }^{17}$.

The individual is able to advance from phase I to phase II when she is able to pick up the card alone, with no clues, and deliver it in the hand of the interlocutor. To move on to phase III, she must be able to find the figure and her communication partner, spontaneously, in any communicative situation. Phase III is finalized when the individual is able to choose the card referring to the item that corresponds to her desires at the moment, discriminating between other cards, and delivering to the communication partner ${ }^{12}$.

However, it is important to note that for the effectiveness and assurance of the efficient implementation of the PECS system, as described in the literature ${ }^{18}$, it is essential to correctly plan the actions by the Speech Therapist, as well as the proper selection of the preferred vocabulary of each individual, since these words will be those responsible for encouraging interpersonal communicative behavior.

After 10 sessions of PECS teaching, combined with the principles of $A B A$ behavioral analysis, the patient acquired the learning criteria proposed in phases I, II and III, being, thus, in the middle of the teaching process, demonstrating good progress, mainly in the acquisition of the operant command. The literature ${ }^{19}$ reports that one of the reasons for the successful 
teaching of the verbal operant "command" in the PECS is that the steps of the protocol create situations that provide functional relations between the patient's response and his environment through motivating contexts (establishing operations), which encourages patients to learn and to order.

Another important result concerns the gains in shared attention, eye contact, social initiations and requests, as well as reduction in behavior problems. A study ${ }^{20}$ has shown that the PECS, in addition to promoting the acquisition of verbal operants, has also made possible the emergence of other behaviors that would not be targets of teaching, such as social smile and eye contact, although not directly related to functional communication.

Throughout the therapy process, music was used as a strategy due to the great interest of the patient. It was noted that in using the music during the session, the patient was able to communicate through verbal means, completing certain passages with a word, and established visual contact with the therapist for approximately 12 seconds. These results are consistent with the literature ${ }^{21}$, which states that through music it is possible to overcome certain barriers present in the ASD to achieve and develop shared attention, thus, favoring a more effective development of communication and social interaction processes.

The participation of the family was considered during the whole therapeutic process, being a great contribution to its success, ensuring the generalization and maintenance of all the skills learned by the adolescent in the family environment. Several authors have emphasized the importance of care for both children and families, enabling parents to participate actively in the therapeutic process, since family engagement with treatment ensures that the therapeutic objectives are expanded in the home context, providing greater synchronicity and communicative and social contingency between the child and the interlocutors ${ }^{22-24}$.

All the gains described could be verified in the result of the ATEC scale answered by the mother. A previous study ${ }^{25}$ revealed that ATEC was a valid, effective, and rapidly completed instrument, as it found a significant correlation between the parents' total scores and scores on the ATEC scale and of the Childhood Autism Rating Scale (CARS), measure established by professional evaluation. In addition, it was noted that the integration of the ATEC tests into health care practice provides important insights into the physical symptoms and overall health of patients, information neglected in most evaluations.

\section{FINAL CONSIDERATIONS}

It can be concluded that, up to now, the PECS associated with $A B A$ principles, together with the use of music, have been effective in teaching functional communication for this adolescent, since the number of figure exchanges has increased independently, also the number of vocalizations with communicative intention, a greater time of eye contact and social smile and even decrease of inappropriate behaviors. It is also important to use scales and standardized tests that can evaluate the therapeutic progress and stimulate the effective participation of the family, regarding the results obtained. It is up to the Speech Therapist to carry out the guidelines, keeping the family aware of the therapeutic process and encouraging the work to be continuous in all the environments attended by the adolescent. Furthermore, it is fundamental to establish the therapeutic setting, thus, building the link with the therapist and enabling the patient to be able to be heard through a warm and effective treatment.

\section{REFERENCES}

1. Teixeira G. Manual do autismo. $2^{-a}$ ed. Rio de Janeiro: Best Seller; 2016.

2. American Psychiatric Association. Diagnostic and statistical manual of mental disorders. $5^{\underline{a}}$ ed. Washington, DC: American Psychiatric Association; 2017.

3. Landa R. Early communication development and intervention for children with autism. Ment Retard Dev Disabil Res Rev. 2007;13(1):16-25.

4. Walter CCF, Nunes DRP. Estimulação da linguagem em crianças com autismo. In: Lamônica DAC (org). Estimulação da linguagem: aspectos teóricos e práticos. São José dos Campos: Pulso; 2008. p.133-62.

5. Bagarollo M, Panhoca A. A constituição da subjetividade de adolescentes autistas: um olhar para as histórias de vida. Rev. Bras. Ed. Esp. 2010;12(2):231-50.

6. Nikolov R, Jonker J, Scahill L. Autismo: tratamentos psicofarmacológicos e áreas de interesse para desenvolvimentos futuros. Rev Bras Psiquiatr. 2006;28(I):S39-46.

7. Eldevik S, Hastings RP, Jahr E, Hughes JC. Outcomes of behavioral intervention for children 
with autism in mainstream pre-school settings. $J$ Autism Dev Disord. 2012;42(2):210-20.

8. Grindle CF, Hastings RP, Saville M, Hughes $\mathrm{JC}$, Huxley $\mathrm{K}$, Kovshoff $\mathrm{H}$ et al. Outcomes of a behavioral education model for children with autism in a mainstream school setting. Behav Modif. 2012;36(3):298-319.

9. Klintwall L, Gillberg C, Bölte S, Fernell E. The efficacy of intensive behavioral intervention for children with autism: a matter of allegiance? J Autism Dev Disord. 2012;42(2):139-40.

10. Fernandes FDM, Amato CALH. Applied behavior analysis and autism spectrum disorders: literature review. CoDAS. 2013;25(3):289-96.

11. Rimland $B$, Edelson M. Autism treatment evaluation checklist (ATEC). Sandiego: CA: Autism Research Institute; 1999.

12. Bondy A, Frost L. Manual de treinamento do sistema de comunicação por troca de figuras. Newark: Pyramid; 2009.

13. Jesus JC, Oliveira TP, Rezende JV. Generalização de mandos aprendidos pelo PECS (Picture Exchange Communication System) em crianças com transtorno do espectro autista. Temas em Psicologia. 2017;25(2):531-43.

14. Marques CFFC, Arruda SLS. Autismo infantil e vínculo terapêutico. Estud. psicol. 2007;24(1):115-24.

15. Hsieh MY, Lynch G, Madison C. Intervention techniques used with autism spectrum disorder by speech-language pathologists in the United States and Taiwan: a descriptive analysis of practice in clinical settings. Am J Speech Lang Pathol. 2018;27(3):1091-104.

16. Oliveira TP, Jesus JC. Análise de sistema de comunicação alternativa no ensino de requisitar por autistas. Psicol Educ. 2016;42:23-33.

17. Rosales R, Rehfeldt RA. Contriving transitive conditioned establishing operations to establish derived manding skills in adults with severe developmental disabilities. J Appl Behav Anal. 2007;40(1):105-21.

18. Ferreira $C$, Bevilacqua $M$, Ishihara $M$, Fiori $A$, Armonia A, Perissinoto $\mathrm{J}$ et al. Selection of words for implementation of the Picture Exchange Communication System - PECS in non-verbal autistic children. CoDAS. 2017;29(1):e20150285.

19. Ziomek MM, Refeldt RA. Investigating the acquisition, generalization, and emergence of untrained verbal operants for mands acquired using the Picture Exchange Communication System in adults with severe developmental disabilities. Anal Verbal Behav. 2008;24(1):15-30.

20. Ganz JB, Davis JL, Lund EM, Goodwyn FD, Simpson RL. Metaanalysis of PECS with individuals with ASD: investigation of targeted versus nontargeted outcomes, participant characteristics, and implementation phase. Research in Developmental Disabilities. 2012;33(2):406-18.

21. Sampaio RT, Loureiro CMV, Gomes CMAA. Musicoterapia e o transtorno do espectro do autismo: uma abordagem informada pelas neurociências para a prática clínica. Per musi. 2015; (32):137-70.

22. Tamanaha AC, Chiari BM, Perissinoto J. The efficacy of the speech and language therapy in autism spectrum disorders. Rev. CEFAC. 2015;17(2):552-8.

23. Spence J, Thurm A. Testing autism interventions: trials and tribulations. Lancet. 2010;375(9732):2124-5.

24. Warren Z, McPheeters ML, Sathe N, Foss-Feig $\mathrm{JH}$, Glasser A, Veenstra-Vanderwelle J. A systematic review of early intensive intervention for autism spectrum disorders. Pediatrics. 2011;127(5):1303-11.

25. Geier DA, Kern JK, Geier MR. A comparison of the Autism Treatment Evaluation Checklist (ATEC) and the Childhood Autism Rating Scale (CARS) for the quantitative evaluation of autism. J Ment Health Res Intellect Disabil. 2013;6(4):255-67. 